NEUROGASTROENTEROLOGY

\title{
Neonatal maternal deprivation triggers long term alterations in colonic epithelial barrier and mucosal immunity in rats
}

\author{
F Barreau, L Ferrier, J Fioramonti, L Bueno
}

Gut 2004;53:501-506. doi: 10.1136/gut.2003.024174

See end of article for authors' affiliations

Correspondence to

Dr J Fioramonti, NeuroGastroenterology and Nutrition Unit, INRA, 180 chemin de Tournefeuille, BP3, 31931 Toulouse cedex 9, France;

jfioramo@toulouse.inra.fr

Accepted for publication 22 October 2003
Background: Stressful events in the early period of life (for example, maternal deprivation) have been shown to modify adult immune and gastrointestinal tract functions. The present study aimed to establish whether maternal deprivation affects colonic epithelial barrier and the development of an experimental colitis in adult rats.

Methods: Male Wistar rat pups were separated during postnatal days 2-14 or left undisturbed with their dam. At 12 weeks of age, we assessed colonic paracellular permeability, bacterial translocation, myeloperoxidase (MPO) activity, mucosal mast cell density, cytokine (interleukin (IL)-1 $\beta$, IL-2, IL-4, IL-10, and interferon $\gamma($ IFN- $\gamma$ )) mRNA expression, and macroscopic damage. Total gut permeability, MPO activity, and macroscopic damage were also assessed four days after intracolonic administration of 2,4,6trinitrobenzenesulphonic acid (TNBS).

Results: Maternal deprivation triggered a significant increase in colonic permeability associated with bacterial translocation into the mesenteric lymph nodes, liver, and spleen. These alterations were associated with some macroscopic damage and an increase in colonic MPO activity, mucosal mast cell density, and cytokine mRNA expression. Intracolonic infusion of TNBS induced a significantly higher inflammatory reaction in separated animals, as judged by enhanced MPO colonic levels, total gut permeability, and macroscopic lesions.

Conclusions: Maternal deprivation promotes long term alterations in the colonic epithelial barrier associated with an exaggerated immune response to an external immune stimulus. This suggests a role for early psychological factors in the regulation of colonic mucosal barrier in later life.
$\mathrm{N}$ eonatal maternal deprivation is a potent stressor which results in permanent behavioural alterations associated with a variety of modifications of neuroendocrine functions. ${ }^{1-3}$ Among these functions, the hypothalamic-pituitary-adrenal (HPA) axis has been largely investigated in rats and it was established that neonatal stress enhances the adrenocortical response to novelty in adult rats. ${ }^{4}$ Neonatal stress also alters immune responses in adults, irrespective of modifications in HPA reactivity. For example, a daily mild stress applied to newborn mice induces long term increased release of Thl type cytokines from splenocytes, associated with decreased release of Th2 type cytokines. ${ }^{5}$ These results suggest possible alterations in inflammatory processes induced in adults by neonatal stress.

Stressful life events have also been found to be associated with gastrointestinal diseases such as Crohn's disease ${ }^{6}$ or irritable bowel syndrome (IBS). ${ }^{7}$ The use of animal models has highlighted the role of neonatal stress in gastrointestinal pathophysiology in adults. For example, early maternal separation has been found to predispose to gastric erosions ${ }^{8}$ and to enhance the stress induced increase in paracellular permeability. ${ }^{9}$ Neonatal stress also increases colonic ion transport but does not affect colonic permeability under basal conditions, as measured by horseradish peroxidase absorption in Ussing chambers. ${ }^{9}$ In rhesus monkeys, maternal separation has also been found to affect the number of colonic lactobacilli, suggesting increased vulnerability to pathogenic bacteria. ${ }^{10}$

Concerning IBS, several reports indicate that loss and separation in the current family in childhood may contribute to the development of IBS in adults. ${ }^{112}$ It has recently been shown in rats that neonatal maternal deprivation triggers long term hypersensitivity to rectal distension, ${ }^{13}{ }^{14}$ which corresponds to the main physiopathological characteristic of IBS in humans. ${ }^{15}$ Recently, Coelho and colleagues ${ }^{16}$ reported that hypersensitivity to rectal distension may be related to elevated colonic paracellular permeability in rats; elevated colonic paracellular permeability induced by activation of colonic proteinase activated receptor 2 has been found to be associated with visceral hyperalgesia to rectal distension. Taken together, these data suggest that neonatal maternal deprivation may alter the colonic epithelial barrier and mucosal immunity in the adult, and may predispose to colonic inflammation and/or hypersensitivity.

Consequently, the aim of this study was to assess the effects of maternal deprivation on colonic paracellular permeability and on subsequent bacterial translocation, myeloperoxidase activity, cytokine expression, and mast cell density. Additionally, we also examined if neonatal maternal deprivation affected immune responsiveness to colonic irritation induced by 2,4,6-trinitrobenzene sulphonic acid (TNBS) in 12 week old rats.

\section{METHODS}

Animals

Male and female Wistar rats (250-275 g) were purchased from Harlan (Gannat, France). One week after arrival in the

Abbreviations: IL, interleukin; IFN- $\gamma$, interferon $\gamma$; $\mathrm{CRH}$, corticotropin releasing hormone; EDTA, ethylenediamine tetraacetic acid; HPA, hypothalamic-pituitary-adrenal axis; IBS, irritable bowel syndrome; $M L N$, mesenteric lymph nodes; MPO, myeloperoxidase; TNBS, 2,4,6trinitrobenzenesulphonic acid; $P C R$, polymerase chain reaction 
animal facility, rats were mated by placing two males and six virgin females in the same cage for two weeks. Pregnant females were then individually housed in standard polypropylene cages containing $2.5 \mathrm{~cm}$ of wood chip bedding material. They were kept at a constant temperature $\left(23 \pm 1{ }^{\circ} \mathrm{C}\right)$ in a pathogen free animal facility, maintained on a 12:12 hour light:dark cycle (lights on at $7 \mathrm{am}$ ). Food (UAR pellets; Epinay, France) and water were available ad libitum. Approximately $50 \%$ of the soiled bedding material was replaced with clean bedding and mixed well twice a week. Such housing was maintained throughout the entire protocol, from isolation of the pregnant females until the experiments were performed at 12 weeks of age.

\section{Maternal deprivation}

After delivery (day 1), litters were culled to 10 pups. Maternal deprivation was performed daily for three consecutive hours (from 9:00 to 12:00 am), during which time pups were removed from their home cage and kept in temperature controlled cages at $28 \pm 1{ }^{\circ} \mathrm{C}$, where bedding was changed every day. During maternal deprivation, pups were individually isolated. This procedure was applied between postnatal days 2 and 14. Control pups were left undisturbed with their dam. From days 15 to 22, all control and maternally deprived pups were maintained with their dam. Weaning was performed on day 22, siblings were sex matched, males were selected, and male siblings were housed in the same cage until experiments were performed at 12 weeks of age. All experimental protocols described in this study were approved by the local Animal Care and Use Committee.

\section{Experimental protocol}

Experiments were conducted in eight groups of 10 rats subjected to maternal deprivation and 10 control rats, at 12 weeks of age. In group 1, total gut paracellular permeability was determined. Selective colonic permeability was measured in group 2. Colonic macroscopic damage, density of mucosal mast cells, myeloperoxidase (MPO) activity, as well as cytokine mRNA in the colon, liver, and spleen were assessed in group 3. Bacterial translocation in mesenteric lymph nodes (MLN), liver, and spleen were examined in group 4. Total gut permeability was measured on the fourth day after induction of colitis with TNBS or after intracolonic saline administration in groups 5 and 6, respectively. Colonic macroscopic damage and MPO activity were assessed four days after intracolonic administration of TNBS or saline in groups 7 and 8 , respectively. Rats in groups 1,2, 5, and 6 were in fact subjected to possible stress when placed in metabolic cages and underwent surgery for insertion of a catheter into the colon (group 2). Rats in groups 3, 4, 7, and 8 were not placed in metabolic cages and subsequently not subjected to any additional stress.

\section{Total gut and colonic paracellular permeability}

Assessment of total gut and colonic permeability to large molecules was performed using ${ }^{51} \mathrm{Cr}$-ethylenediamine tetraacetic acid (EDTA) as a selective marker of paracellular permeation of tight junctions. To determine total gut permeability, $0.7 \mu \mathrm{Ci}$ of ${ }^{51} \mathrm{Cr}$-EDTA (Perkin Elmer Life Science, Paris, France) was diluted in $500 \mu \mathrm{l}$ of saline and administered by the oral route. To measure colonic permeability, rats were anaesthetised with ketamine $(100 \mathrm{mg} / \mathrm{kg})$ and acepromazine $(0.5 \mathrm{mg} / \mathrm{kg})$ at 11 weeks of age, and a catheter was implanted in the proximal colon $(1 \mathrm{~cm}$ from the caecocolic junction), attached to the abdominal muscle wall, and exteriorised at the back of the neck. ${ }^{51} \mathrm{Cr}$-EDTA, diluted in $250 \mu \mathrm{l}$ of saline, was injected intracolonically through the catheter. Animals were then placed in metabolic cages, and faeces and urine were collected for 24 hours. Total radioactivity found in urine was measured with a gamma counter (Cobra II; Packard, Meriden, Connecticut, USA). Permeability to ${ }^{51} \mathrm{Cr}$-EDTA was expressed as a percentage of the total radioactivity administered. To become accustomed to their new environment, rats were placed in metabolic cages for three days before ${ }^{51} \mathrm{Cr}$-EDTA administration.

\section{Macroscopic damage score}

Rats were sacrificed and colonic damage scores were determined macroscopically in a blinded fashion, according to the criteria of Wallace and Keenan, ${ }^{17}$ taking into account the severity and extent of visible damage, presence and severity of adhesions, and presence or absence of diarrhoea. Finally, the whole colon was harvested and weighed.

\section{Myeloperoxidase activity}

MPO activity, a marker of polymorphonuclear neutrophils granules, was assessed in colon tissues according to the Bradley method. ${ }^{18}$ Samples of distal colon $(1 \mathrm{~cm})$ were suspended in a potassium phosphate buffer $(50 \mathrm{mM}$, $\mathrm{pH}$ 6.0) and homogenised in ice. Three cycles of freeze/thaw were undertaken. Suspensions were then centrifuged at $10000 \mathrm{~g}$ for 15 minutes at $4^{\circ} \mathrm{C}$. Supernatants were discarded and pellets were resuspended in hexadecyl trimethylammonium bromide buffer $(0.5 \% \mathrm{w} / \mathrm{v}$, in $50 \mathrm{mM}$ potassium phosphate buffer, $\mathrm{pH}$ 6.0). These suspensions were sonicated on ice and centrifuged again at $10000 \mathrm{~g}$ for 15 minutes at $4^{\circ} \mathrm{C}$. The supernatants obtained were diluted in potassium phosphate buffer ( $\mathrm{pH} \mathrm{6.0)}$ containing $0.167 \mathrm{mg} / \mathrm{ml}$ of O-dianisidine dihydrochloride and $0.0005 \%$ of hydrogen peroxide. MPO from human neutrophils $(0.1$ units/100 $\mu \mathrm{l})$ was used as a standard. Kinetic changes in absorbance at $450 \mathrm{~nm}$, every 10 seconds over two minutes, were recorded with a spectrophotometer. One unit of MPO activity was defined as the quantity of MPO degrading $1 \mu \mathrm{mol}$ of hydrogen peroxide $/ \mathrm{min} / \mathrm{ml}$ at $25^{\circ} \mathrm{C}$. Protein concentration was determined using the commercial kit of the modified method of Lowry (Detergent Compatible Assay; Biorad, Marnes la Coquette, France) and MPO activity was expressed as units/per gram of protein.

\section{Bacterial translocation}

Liver, spleen, and MLN were tested for translocated bacteria. After sacrifice, an incision was made with sterile instruments through the skin and peritoneum of the abdomen. The liver, spleen, and MLN were removed and weighed aseptically.

The organs were homogenised (sonication over $10 \mathrm{~min}$ utes) and serial dilutions of aliquots were plated onto blood agar to count total anaerobic bacteria and onto standard tryptase soja agar to count total aerobic bacteria. Plates were incubated for 72 hours at $37^{\circ} \mathrm{C}$ under aerobic or anaerobic conditions and the number of colony forming units was counted. Bacterial translocation was expressed as the percentage of positive organs for aerobic and anaerobic bacteria.

\section{Mast cell number}

A $2 \mathrm{~cm}$ long portion of the colon was surgically excised and washed in sterile saline. The collected fragments were fixed in Carnoy's solution, embedded in paraffin blocks, and cut into $5 \mu \mathrm{m}$ sections. Transverse paraffin sections were stained with alcian blue-Safranin. Mast cell number, expressed as the number of mucosal mast cells per square millimetre of mucosa, was evaluated using an image grabbing program and the image analysis software Optilab Pro 2.6.1 (Graftek, Voisins le Bretonneux, France).

\section{Cytokine mRNA expression}

Total mRNA from rat colon, liver, and spleen was isolated using Extractall reagent (Eurobio, les Ulis, France). RNA 
samples $(1 \mu \mathrm{g})$ were reverse transcripted into complementary DNA (cDNA) using 200 units of Murine-Moloney leukaemia virus (Invitrogen, Cergy Pontoise, France), $500 \mu \mathrm{g} / \mathrm{ml}$ oligo$\mathrm{dT}$, and $2.5 \mathrm{mM}$ of each of the four deoxyribonucleotide triphosphates (dNTP; Invitrogen) in a final reaction volume of $20 \mu \mathrm{l}$ in the presence of $40 \mathrm{U} / \mu \mathrm{l}$ of ribonuclease inhibitor (Invitrogen). Samples were incubated at $37^{\circ} \mathrm{C}$ for 50 minutes, followed by 15 minutes at $70^{\circ} \mathrm{C}$ to inactivate the enzyme. Then, samples were stored at $-80^{\circ} \mathrm{C}$ until use. The reverse transcripted reaction mixture $(1 \mu \mathrm{l})$ was amplified by polymerase chain reaction (PCR) using sense and antisense primers specific for: G3PDH, 5'-ATCACCATCTTCCAGGAGCG-3' and 5'-TTCTGAGTGGCAGTGAGGGC-3'; interleukin (IL) - $1 \beta, 5^{\prime}$-GACAGAACATAAGCCAACAAG-3' and $5^{\prime}$-GTCAACTATGTCCCGACCATT-3'; IL-2, 5'-ACAAGAATCTGAAACTCCCC-3' and 5'-GAGATGATGCTTTGACAGATGG-3'"; IL-4, 5'-TACGGCAACAAGGAACACCAAGG-3' and 5'-GAAGTCTTTCAGTGTTGTGAGC-3'; IL-10, 5'-CTTACTGGCTGGAGTGAAGACC-3' and 5'-AATCATTCTTCACCTGCTCC-3'; and interferon $\gamma($ IFN- $\gamma), 5^{\prime}$-CTCTCTGGCTGTTACTGC-3' and 5' GACTCCTTTTCCGCTTCC-3'. The PCR reaction was performed in the presence of $1.25 \mathrm{U} /$ reaction of AmpliTaq Gold DNA polymerase (Applied Biosystems, Courtaboeuf, France), $2.5 \mathrm{mM}$ of each of the four desoxyribonucleotide triphosphates, and 50 pmol of sense and antisense primers, in a final reaction volume of $50 \mu \mathrm{l}$. Amplification was performed by a different number of cycles consisting of denaturation for one minute at $94^{\circ} \mathrm{C}$, primer annealing for one minute at $53^{\circ} \mathrm{C}$, and primer extension for one minute at $72^{\circ} \mathrm{C}$. Then, amplicons were stained with SYBR Gold (Molecular Probes, Leiden, the Netherlands) and separated by electrophoresis in 3\% agarose gel for one hour at $100 \mathrm{~V}$. The ratio between the amount of G3PDH cDNA and cytokine cDNA was calculated using an image analyser (Quantity One software; Biorad, France).

\section{TNBS induced colitis}

Under ketamine ( $100 \mathrm{mg} / \mathrm{kg})$ and acepromazine $(0.5 \mathrm{mg} / \mathrm{kg})$ anaesthesia, colitis was induced in 12 week old rats by a single intracolonic administration of $40 \mathrm{mg} / \mathrm{kg}$ TNBS (Fluka, Saint Quentin Fallavier, France) dissolved in 50\% ethanol. A $100 \mu \mathrm{l}$ aliquot of the freshly prepared solution was injected into the colon, $7 \mathrm{~cm}$ from the anus, using a polyethylene catheter (OD $2 \mathrm{~mm}$ ). Four days after TNBS infusion, body weight, gastrointestinal permeability, macroscopic damage score, and MPO activity were assessed.

\section{Data analysis and statistics}

Values are expressed as mean (SEM). Statistical analysis of the data concerning the effects of neonatal stress under basal conditions was performed using the non-parametric MannWhitney test, where relevant. To determine the incidence of neonatal stress on bacterial translocation, a contingency table and Fisher's exact test were used to analyse the differences.

Differences were considered significant at $\mathrm{p}<0.05$. Changes related to TNBS treatment were analysed by two way ANOVA, with stress and inflammation as fixed factors. The interaction between these two factors was considered significant at $\mathrm{p}<0.05$.

\section{RESULTS}

\section{Body weight}

Separated rats gained less weight than controls during the period of maternal separation and until the seventh postnatal week. Then, weight gain was similar in both groups, but separated rats at 12 weeks still weighed less than controls (317.1 (6.1) v 349.0 (5.6) g, respectively; $\mathrm{p}<0.05$ ).

\section{Paracellular permeability}

In 12 week old rats, $2.2(0.2) \%$ of orally administered ${ }^{51} \mathrm{Cr}$ EDTA (total gut permeability) was excreted in urine over 24 hours following administration. This value was significantly increased by $95 \%(4.3(0.4) \%$; p $<0.05)$ in maternally deprived rats (fig 1A).

Recovery of ${ }^{51} \mathrm{Cr}$-EDTA when injected through the colonic catheter (colonic permeability) was $2.3(0.4)$ and $4.2(0.6) \%$ $(\mathrm{p}<0.05)$ in control and maternally deprived rats, respectively, corresponding to a $82 \%$ increase (fig lB). Urinary volumes over 24 hours were similar in both groups.

\section{Bacterial translocation}

In 12 week old control rats, no bacteria were detected in the liver, spleen, or MLN. In maternally deprived rats, a concentration of aerobic bacteria of $2 \mathrm{log} \mathrm{CFU} / \mathrm{g}$ tissue was observed in $90 \%, 81.8 \%$, and $75 \%$ of animals in the liver, spleen, and MLN, respectively. Anaerobic bacteria were also present ( $2 \log \mathrm{CFU} / \mathrm{g}$ tissue) in the three extraintestinal organs in $72.9 \%$ (liver), $54.5 \%$ (spleen), and $80.0 \%$ (MLN) of animals.

\section{Colonic morphology}

The weight of the colon was slightly but significantly $(\mathrm{p}<0.001)$ increased in maternally deprived rats in comparison with controls $(1.60(0.04) v 1.30(0.06) \mathrm{g})$.

Focal hyperaemia was detected in $10 \%$ ( $1 / 10$ animals $)$ of controls and 70\% (7/10 animals) of maternally deprived rats. No mesenteric adhesions were found in controls but they were present in $60 \%$ of deprived animals. These alterations corresponded to a macroscopic damage score of $0.1(0.1)$ in controls and $1.3(0.1)$ in deprived rats $(\mathrm{p}<0.05)$.

\section{Myeloperoxidase and mast cells}

In control rats, colonic MPO activity was 128 (21) U/g of protein, and this activity was significantly higher (426 (69); $\mathrm{p}<0.05$ ) in maternally deprived rats (fig 2A).

The density of colonic mucosal mast cells was also higher $(\mathrm{p}<0.05)$ in maternally separated rats $\left(133(22) / \mathrm{mm}^{2}\right)$ compared with controls $\left(85(8) / \mathrm{mm}^{2}\right)$ (fig $\left.2 \mathrm{~B}\right)$.

\section{Cytokine expression}

mRNA expression of IFN- $\gamma$, IL-1 $\beta$, IL-2, IL-4, and IL-10 in colonic, liver, and spleen was significantly higher $(p<0.05)$ in maternally deprived rats than in controls. The increase varied from $60 \%$ (IFN- $\gamma$ in the liver) to $1600 \%$ (IL-2 in the colon) (table 1$)$.
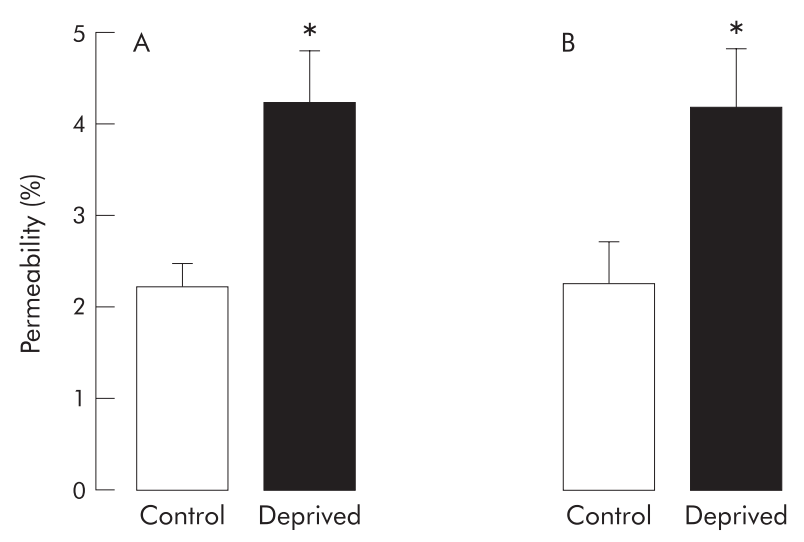

Figure 1 Effect of neonatal stress on total gut (A) and colonic (B) paracellular permeability in 12 week old rats. Values are mean (SEM) ( $n=8$ in each group). ${ }^{*} p<0.05$ between deprived and control rats. 



Figure 2 Effect of neonatal stress on colonic myeloperoxidase (MPO) activity (A) and mucosal mast cell number (B) in 12 week old rats. Values are mean (SEM) ( $n=8$ in each group). ${ }^{*} p<0.05$ between deprived and control rats.

Under basal conditions, neonatal maternal deprivation induced a low systemic inflammatory state reflected by elevated IL-1 $\beta$ expression in the colon, liver, and spleen. Moreover, maternal deprivation increased both Thl (IFN- $\gamma$ and IL-2) and Th2 (IL-4 and IL-10) cytokine profiles in the three organs.

\section{TNBS induced colitis}

Four days after intracolonic instillation of TNBS, loss in body weight was observed in all animals. This loss was significantly higher $(\mathrm{p}<0.05)$ in separated rats $(-12(1.2) \mathrm{g})$ than in controls $(-8(0.6) \mathrm{g})$. In control rats, the colonic damage score was 7.0 (0.4), colonic MPO activity 3980 (641) U/g protein, and total gut permeability $7.8(0.3) \%$. All of these values were significantly increased $(p<0.05)$ in maternally deprived rats: colonic damage score was 8.7 (0.3), colonic MPO activity 6727 (830) U/g, and total gut permeability 10.3 $(0.6) \%$ (fig 3). Moreover, statistical analysis showed that neonatal maternal deprivation enhanced significantly $(p<0.05$, two way ANOVA) the increases in total gut paracellular permeability, colonic MPO activity, and macroscopic damage scores.

\section{DISCUSSION}

Our data show that repeated maternal deprivation during the early postnatal period induces long term alterations in the colonic epithelial barrier. This is the first report demonstrating that repeated maternal separation leads to an increase in colonic paracellular permeability in adult life under basal conditions and in response to colonic inflammation. Moreover, repeated maternal separation delays the gain in body weight, as previously reported by Soderholm and colleagues, ${ }^{9}$ and favours the development of mesenteric adherence with or without focal hyperaemia, associated with elevated colonic weight. We also demonstrated for the first time that neonatal stress induces bacterial translocation into the liver, spleen, and MLN. Theses alterations are concomitant with an elevated number of colonic mucosal mast cells and increased expression of mRNA encoding IL-1 $\beta$, IL-2, IL-4, IL-10, and IFN- $\gamma$ in colonic mucosa, liver, and spleen, reflecting immune mucosal stimulation. Moreover, our results also show that neonatal stress exacerbates the inflammatory response to TNBS.

The neonatal period, roughly extending in rats from birth to day 14, is often referred to as a stress hyporesponsive period characterised by a diminished adrenocorticotropin and corticosterone response to most stressors. ${ }^{19}$ This period is overcome by applying a severe stressor such as prolonged maternal deprivation. ${ }^{20}$ Overcoming this period may be responsible for alterations in the HPA axis and numerous long term disorders, such as anxiety, depression, and feeding behaviour abnormalities. Concerning gut functions, neonatal stress has already been shown to increase gastric ulcer susceptibility in the adult. ${ }^{821} 22$ However, in these studies, neonatal stress consisted of early weaning, and milk deprivation has been proposed as a major factor involved in this increased ulcer susceptibility. Recent studies have suggested that neonatal maternal deprivation predisposes adult rats to colonic barrier dysfunction in response to mild stress $^{9}$ and triggers long term changes in colonic sensitivity to rectal distension. ${ }^{13}{ }^{14}$ However, Soderholm and colleagues 9 reported that, under basal conditions, neonatal separation increases colonic mucosal ion transport but does not modify colonic permeability, evaluated by transmucosal flux of horseradish peroxidase in Ussing chambers. They found that colonic permeability was dramatically increased after a mild acute stress in separated but not in control rats. In our study, we found that both total gut and colonic permeability were increased in separated animals under basal conditions. One can argue that placing the rat in a metabolic cage for 24 hours and surgery for insertion of a catheter into the colon in one group of rats are stressful events and that we did not measure permeability under basal conditions. However, all other alterations in the mucosal barrier, in agreement with an increase in permeability, were observed in the absence of stress induced by placing the animals in metabolic cages.

The increase in colonic paracellular permeability that we observed in deprived rats could be explained by different mechanisms. Firstly, repeated maternal deprivation may affect the HPA axis. Biagini and colleagues ${ }^{4}$ have reported that repeated neonatal stress ( 5 hours/day from postnatal days 2 to 6) increases basal plasma levels of corticosterone in 45 day old rats. It has been shown recently that acute stress increases gastrointestinal paracellular permeability. ${ }^{23}$ The fact that the stress induced increase in gastrointestinal

Table 1 Effect of neonatal stress on the cytokine profile of rat colon, liver, and spleen

\begin{tabular}{|c|c|c|c|c|c|c|}
\hline & \multicolumn{2}{|l|}{ Colon } & \multicolumn{2}{|l|}{ Liver } & \multicolumn{2}{|l|}{ Spleen } \\
\hline & Control & Deprived & Control & Deprived & Control & Deprived \\
\hline $\mathrm{IFN}-\gamma$ & $0.07(0.02)$ & $0.21(0.06)^{*}$ & $0.10(0.01)$ & $0.16(0.01)^{*}$ & $0.06(0.01)$ & $0.19(0.03)^{*}$ \\
\hline IL-1 $\beta$ & $0.35(0.04)$ & $1.90(0.60)^{*}$ & $0.50(0.05)$ & $2.60(0.20)^{*}$ & $0.90(0.10)$ & $2.60(0.20)^{*}$ \\
\hline IL-2 & $0.04(0.01)$ & $0.68(0.20)^{*}$ & $0.04(0.01)$ & $0.07(0.02)$ & $0.1(0.02)$ & $0.7(0.07)^{*}$ \\
\hline IL-4 & $0.05(0.01)$ & $0.15(0.03)^{*}$ & $0.09(0.01)$ & $0.15(0.02)^{*}$ & $0.07(0.01)$ & $0.12(0.03)^{*}$ \\
\hline IL-10 & $0.10(0.03)$ & $0.36(0.07)^{*}$ & $0.04(0.01)$ & $0.14(0.03)^{*}$ & $0.05(0.01)$ & $0.22(0.05)^{*}$ \\
\hline
\end{tabular}

Values are mean (SEM); $\mathrm{n}=8$.

Results are expressed as the ratio cytokine/G3PDH.

IL, interleukin; IFN- $\gamma$, interferon $\gamma$.

* $\mathrm{p}<0.05$ between deprived and control rats (Mann-Whitney's test). 

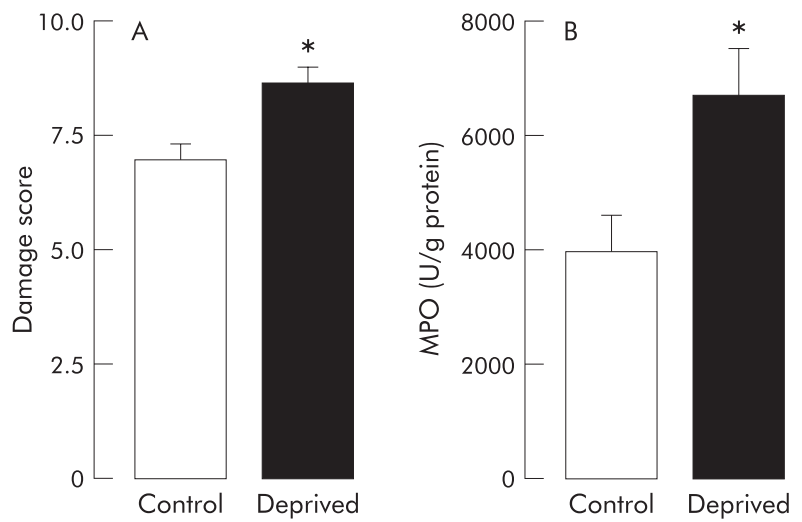

paracellular permeability disappears after adrenalectomy or pharmacological blockade of glucocorticoid receptors strongly supports the fact that this effect is linked to elevated corticosterone plasma levels. However, in another study, ${ }^{24}$ no difference was found in basal corticosterone plasma levels between control and maternally deprived rats. The protocol of neonatal maternal deprivation used in our study was similar to that used by Biagini and colleagues, ${ }^{4}$ and direct involvement of corticoids in the increase in colonic paracellular permeability cannot be excluded.

We can also hypothesise that early life stress related to maternal deprivation may affect colonic resident bacteria that in turn may affect the basal level of paracellular permeability, allowing bacterial translocation and triggering immune activation in the colon. Neonatal psychological disturbances have been found to affect the integrity of the endogenous microflora in rhesus monkeys and especially to decrease the colonic lactobacilli population. This lactobacilli population is known to inhibit colonisation and proliferation of pathogenic bacteria and to play a protective role in the intestinal mucosa. ${ }^{10}$ Moreover, stress promotes translocation of nonendogenous bacteria found to induce activation of the HPA axis which may be responsible for the prolonged increase in paracellular permeability. ${ }^{25}$ Again, as we did not measure corticosteronaemia, we have no evidence for involvement of the HPA axis in the increased permeability we observed. Moreover, Soderholm and colleagues ${ }^{9}$ have shown that corticotropin releasing hormone $(\mathrm{CRH})$ may be involved at the periphery in the stress induced increase in colonic permeability observed in separated rats. Consequently, a direct local action of CRH can be supposed and may be independent of the HPA axis.

Repeated stress has been shown to increase the number of colonic mucosal mast cells which play an important role in the stress induced increase in gut paracellular permeability as these alterations by stress were not observed in mast cell deficient $W s / W s$ rats. ${ }^{26}$ Herein, we observed that maternal deprivation increased the number of colonic mucosal mast cells in adult rats. Similar results have been reported at the level of the central nervous system where increased mast cell numbers have been found within the thalamus nuclei after daily handling of newborn rats. ${ }^{27}$ Moreover, an elevated density of mast cells in the thalamus nuclei may induce transient abnormalities within the cerebral vasculature and blood-brain barrier. ${ }^{28}$ Therefore, this increased density of colonic mucosal mast cells may contribute to the increase in colonic paracellular permeability through a facilitation to degranulate.

Whatever the relevance of these hypotheses, the increase in colonic paracellular permeability is certainly involved in favouring bacterial translocation which in turn stimulates the colonic mucosal immune system subsequent to antigen or

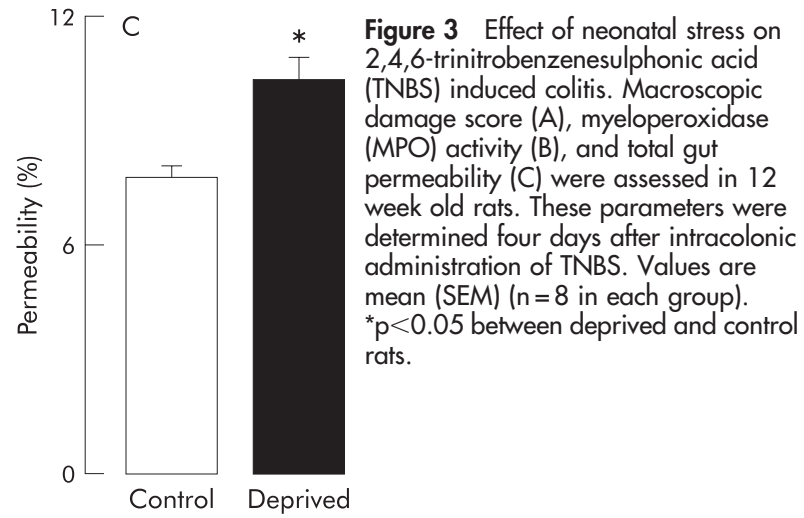

toxin penetration. The hypothesis of a primary effect on intestinal permeability is reinforced by recent data showing that when a stress induced increase in permeability is pharmacologically blocked by inhibiting myosin light chain phosphorylation of epithelial cells, bacterial translocation is abolished..$^{29}$ Bacterial translocation is described as enhancing the host immune system, including mucosal (secretory immunoglobulins), cell mediated (macrophages and T cells), and humoral (serum immunoglobulins) immunity. ${ }^{30}$ Colonic mucosal cytokine expression may be considered as reflecting this immune stimulation. Immune system activation is evidenced by enhanced levels of mRNA encoding cytokines such as IL- $1 \beta$, IL-2, IL-4, IL-10, and IFN- $\gamma$ in the colon, liver, and spleen, where bacterial translocation was detected. Among the cytokines we found overexpressed after maternal deprivation, IL-4 and IFN- $\gamma$ are known to be directly involved in controlling intestinal paracellular permeability. ${ }^{31}$ Indeed, the immune cells ( $\mathrm{T}$ and $\mathrm{B}$ lymphocytes, macrophages, eosinophils, neutrophils) present in the lamina propria can release proinflammatory cytokines ${ }^{31}{ }^{32}(\mathrm{IFN}-\gamma, \mathrm{TNF}-\alpha)$ and anti-inflammatory interleukin ${ }^{33}$ (IL-4), which are described as acting on membrane receptors of epithelial cells to increase tight junction permeability. ${ }^{32}$ IFN- $\gamma$ mRNA overexpression in these organ is in agreement with studies showing that repeated stress in the neonatal period is associated with long term release of IFN- $\gamma$ by splenocytes in later life. ${ }^{5}$ Interestingly, we found a similar increase in the passage of Cr-EDTA in urine of maternally deprived rats after intragastric gavage and intracolonic administration. This suggests that neonatal stress probably has a major effect on colonic rather than intestinal paracellular permeability, but an effect on small intestine permeability cannot be excluded. Using other markers, it has been shown that acute stress increases epithelial permeability in all regions of the gastrointestinal tract $^{23}$ but it remains difficult to compare the immediate effects of an acute stress to the long term effects of neonatal stress.

We have also shown that repeated maternal deprivation exacerbates the severity of TNBS induced colitis, as evidenced by the increase in all parameters characterising colonic inflammation. Several mechanisms may explain this increased susceptibility to inflammation. In adult rats, repeated stress applied for four days before or after TNBS infusion enhanced the inflammatory response to TNBS. ${ }^{34}$ The enhancement of colitis by stress has been found to be aggravated by intracerebroventricular administration of a CRH receptor antagonist, ${ }^{34}{ }^{35}$ suggesting a protective role of brain CRH related to superimposed activation of the HPA axis in TNBS induced colitis. Maternal separation has been found to induce profound and long lasting changes in the functioning of the HPA axis and to increase basal levels of $\mathrm{CRH}$ in the central nervous system of adult rats. ${ }^{36}$ However, 
this possible elevated basal level of $\mathrm{CRH}$ in the central nervous system does not prevent the effect of neonatal stress at variance with the central protective effect of CRH, as seen for short periods of stress and also proposed to explain strain differences in susceptibility to colonic inflammation. ${ }^{3435}$ Nevertheless, we can speculate that chronic elevated levels of CRH in the central nervous system may be associated with a low or mild response of the HPA axis during TNBS induced colitis, and could be involved in exacerbation of inflammatory responses induced by repeated maternal deprivation. On the other hand, the effects of maternal deprivation on peripheral $\mathrm{CRH}$ levels have not been investigated but this hormone has been suggested to be involved at the peripheral level in the genesis of epithelial alterations related to stress in adult rats. ${ }^{96}{ }^{37}$ Consequently, we cannot exclude the fact that altered $\mathrm{CRH}$ levels in gut tissues in neonatal maternal deprived rats may participate in exacerbation of colitis.

Another possible explanation for this exacerbation of colitis severity induced by neonatal maternal deprivation is linked to alteration in colonic mucosal immune status observed in deprived rats. Indeed, a number of studies have shown that dysregulation of the mucosal immune system is a major contributing factor to the pathogenesis of inflammatory bowel disease. ${ }^{38}{ }^{39}$ Further, excessive production of IFN- $\gamma$ and exaggerated Thl-type responses are key immunological events in the induction of inflammation in different experimental models. ${ }^{40}$ Thus we can hypothesise that elevated basal levels of colonic mucosal IFN- $\gamma$ mRNA expression associated with alterations in tight junction permeability observed in deprived rats strongly enhances the inflammatory response to TNBS colitis.

In summary, this study shows that neonatal stress has long term consequences for gut paracellular permeability, associated with diffuse bacterial translocation. In agreement with other studies showing that neonatal stress stimulates the immune system, we report activation of the colonic mucosal immune system. This suggests a key role for early stressful events in the regulation of the colonic mucosal barrier, and could have implications in the development of intestinal disorders such as IBS and/or inflammatory bowel disease in later life.

\section{ACKNOWLEDGEMENTS}

This work was supported by the Institut National de la Recherche Agronomique (INRA), Paris, France. We thank Bernard Joseph for his technical assistance.

\section{Authors' affiliations}

F Barreau, L Ferrier, J Fioramonti, L Bueno, Neurogastroenterology and Nutrition Unit, Institut National de la Recherche Agronomique, Toulouse, France

\section{REFERENCES}

1 Jurcovicova J, Dobrakovova M. Repeated maternal deprivation alters behavioral pattern and attenuates prolactin response to mild stressor in adult male wistar rats. Endocr Regul 1998;32:161-5.

2 Kuhn CM, Butler SR, Schanberg SM. Selective depression of serum growth hormone during maternal deprivation in rat pups. Science 1978;201:1034-6.

3 Kuhn CM, Pauk J, Schanberg SM. Endocrine responses to mother-infant separation in developing rats. Dev Psychobiol 1990;23:395-410.

4 Biagini G, Pich EM, Carani C, et al. Postnatal maternal separation during the stress hyporesponsive period enhances the adrenocortical response to novelty in adult rats by affecting feedback regulation in the CA1 hippocampal field. Int J Dev Neurosci 1998;16:187-97.

5 Loizzo A, Loizzo S, Lopez L, et al. Naloxone prevents cell-mediated immune alterations in adult mice following repeated mild stress in the neonatal period. Br J Pharmacol 2002;135:1219-26.

6 Ringel Y, Drossman DA. Psychosocial aspects of Crohn's disease. Surg Clin North Am 2001;81:231-52.

7 Mayer EA, Naliboff BD, Chang L, et al. V. Stress and irritable bowel syndrome. Am J Physiol Gastrointest Liver Physiol 2001;280:G519-24.
8 Ackerman SH, Hofer MA, Weiner $\mathrm{H}$. Predisposition to gastric erosions in the rat: behavioral and nutritional effects of early maternal separation. Gastroenterology 1978;75:649-54.

9 Soderholm JD, Yates DA, Gareau MG, et al. Neonatal maternal separation predisposes adult rats to colonic barrier dysfunction in response to mild stress. Am J Physiol Gastrointest Liver Physiol 2002;283:G1257-63.

10 Bailey MT, Coe CL. Maternal separation disrupts the integrity of the intestinal microflora in infant rhesus monkeys. Dev Psychobiol 1999;35:146-55.

11 Hislop IG. Childhood deprivation: an antecedent of the irritable bowel syndrome. Med J Aust 1979;1:372-4.

12 Lowman BC, Drossman DA, Cramer EM, et al. Recollection of childhood events in adults with irritable bowel syndrome. J Clin Gastroenterol 1987:9:324-30.

13 Coutinho SV, Plotsky PM, Sablad M, et al. Neonatal maternal separation alters stress-induced responses to viscerosomatic nociceptive stimuli in rat. Am J Physiol Gastrointest Liver Physiol 2002;282:G307-16.

14 Rosztoczy A, Fioramonti J, Jarmay J, et al. Influence of sex and experimental protocol on the effect of maternal deprivation on rectal sensitivity to distension in the adult rat. Neurogastroenterol Motil 2003;15:679-86.

15 Whitehead WE, Holtkotter B, Enck P, et al. Tolerance for rectosigmoid distention in irritable bowel syndrome. Gastroenterology 1990;98:1187-92.

16 Coelho AM, Vergnolle N, Guiard B, et al. Proteinases and proteinaseactivated receptor 2: a possible role to promote visceral hyperalgesia in rats. Gastroenterology 2002;122:1035-47.

17 Wallace JL, Keenan CM. An orally active inhibitor of leukotriene synthesis accelerates healing in a rat model of colitis. Am J Physiol 1990;258:G527-34.

18 Bradley PP, Priebat DA, Christensen RD, et al. Measurement of cutaneous inflammation: estimation of neutrophil content with an enzyme marker. J Invest Dermatol 1982;78:206-9.

19 Rosenfeld P, Gutierrez YA, Martin AM, et al. Maternal regulation of the adrenocortical response in preweanling rats. Physiol Behav 1991;50:661-71.

20 Cirulli F, Santucci D, Laviola G, et al. Behavioral and hormonal responses to stress in the newborn mouse: effects of maternal deprivation and chlordiazepoxide. Dev Psychobiol 1994;27:301-16.

21 Ackerman SH, Hofer MA, Weiner H. Early maternal separation increases gastric ulcer risk in rats by producing a latent thermoregulatory disturbance. Science 1978;201:373-6.

22 Glavin GB, Pare WP. Early weaning predisposes rats to exacerbated activitystress ulcer formation. Physiol Behav 1985;34:907-9.

23 Meddings JB, Swain MG. Environmental stress-induced gastrointestinal permeability is mediated by endogenous glucocorticoids in the rat. Gastroenterology 2000;119:1019-28.

24 Suchecki D, Tufik S. Long-term effects of maternal deprivation on the corticosterone response to stress in rats. Am J Physiol 1997;273:R1332-8.

25 Ando T, Brown RF, Berg RD, et al. Bacterial translocation can increase plasma corticosterone and brain catecholamine and indoleamine metabolism. Am J Physiol Regul Integr Comp Physiol 2000;279:R2164-72.

26 Santos J, Yang PC, Soderholm JD, et al. Role of mast cells in chronic stress induced colonic epithelial barrier dysfunction in the rat. Gut 2001;48:630-6.

27 Persinger MA. Developmental alterations in mast cell numbers and distributions within the thalamus of the albino rat. Dev Neurosci $1981 ; 4: 220-4$

28 Lafreniere GF, Persinger MA, Lafreniere RF. Effects of permanent residence with foster mothers and new siblings upon numbers of mast cells within the thalamus of preweaned rats. Psychol Rep 2001;88:625-6.

29 Ferrier L, Mazelin L, Cenac N, et al. Stress-induced disruption of colonic epithelial barrier: Role of interferon-gamma and myosin light chain kinase in mice. Gastroenterology 2003;125:795-804.

30 Berg RD. Bacterial translocation from the gastrointestinal tract. Trends Microbiol 1995;3:149-54.

31 McKay DM, Baird AW. Cytokine regulation of epithelial permeability and ion transport. Gut 1999;44:283-9.

32 Perdue MH. Mucosal immunity and inflammation. III. The mucosal antigen barrier cross talk with mucosal cytokines Am J Physiol 1999;277:G1-5.

33 Berin MC, Yang PC, Ciok L, et al. Role for IL-4 in macromolecular transport across human intestinal epithelium. Am J Physiol 1999;276:C1046-52.

34 Gue M, Bonbonne C, Fioramonti J, et al. Stress-induced enhancement of colitis in rats: CRF and arginine vasopressin are not involved. Am J Physiol 1997;272:G84-91.

35 Million M, Tache Y, Anton P. Susceptibility of Lewis and Fischer rats to stressinduced worsening of TNB-colitis: protective role of brain CRF. Am J Physiol 1999;276:G1027-36.

36 Plotsky PM, Meaney MJ. Early, postnatal experience alters hypothalamic corticotropin-releasing factor (CRF) mRNA, median eminence CRF content and stress-induced release in adult rats. Brain Res Mol Brain Res 1993; 18:195-200.

37 Saunders PR, Santos J, Hanssen NP, et al. Physical and psychological stress in rats enhances colonic epithelial permeability via peripheral CRH. Dig Dis Sci 2002;47:208-15.

38 Braegger CP, MacDonald TT. Immune mechanisms in chronic inflammatory bowel disease. Ann Allergy 1994;72:135-41

39 Brandtzaeg P, Haraldsen G, Rugtveit J. Immunopathology of human inflammatory bowel disease. Springer Semin Immunopathol 1997; 18:555-89.

40 Kuhn R, Lohler J, Rennick D, et al. Interleukin-10-deficient mice develop chronic enterocolitis. Cell 1993;75:263-74. 